\title{
Magistério: que lugar é esse?
}

\author{
Teaching: what place is that?
}

\section{Magisterio: ¿qué lugar es ese?}

\begin{abstract}
Lilian Alves Pereira'
Universidade Regional de Blumenau, Pesquisadora do Grupo de Pesquisa Políticas de Educação na Contemporaneidade

Gicele Maria Cerui ${ }^{2}$

Universidade Regional de Blumenau, Professora e Coordenadora do Programa de Pósgraduação em Educação, Coordenadora do grupo de pesquisa Políticas de Educação na Contemporaneidade
\end{abstract}

Resumo: A formação de professores para a Educação Infantil e anos iniciais do Ensino Fundamental tinha como lócus para acontecer no nível médio. Em 1996, com a promulgação da LDB n. 9.394, essa modalidade de formação docente foi imersa em um ambíguo contexto. Ao mesmo tempo que a legislação prevê a formação docente em nível superior, o curso de Magistério permanece em funcionamento, e, assim, professores que se formam neste continuam sendo contratados. Este artigo foi elaborado a partir de uma pesquisa documental, a qual teve por objetivo analisar a política de formação dos professores. Os objetivos específicos foram contextualizar a formação de professores em nível médio no Brasil, além disso, discutir a política de formação de professores a partir da metodologia de análise Abordagem do Ciclo de Políticas proposta por Ball e seus colaboradores. A discussão está ancorada principalmente em Ball, Foucault, Mainardes, Tanuri, Villela e Schaffrath. Apesar de haver leis que apontam o nivel superior como lócus privilegiado para a formação do professor, elas não significaram o fim da formação em nível médio. 0 mesmo sistema educacional que coloca em xeque a formação de professores em nível médio oferece essa formação e contrata os docentes formados por ela. A formação em nível médio e em nível superior coabitam no contexto da prática.

Palavras-chave: Ensino médio. Ensino superior. Formação de professores. Política pública.

Abstract: The teachers' formation for Early Childhood Education and early years of Elementary Education had as a locus for the middle level to happen. In 1996, with the enactment of LDB n. 9.394, this form of teacher training was immersed in an ambiguous context. At the same time as the legislation provides for teacher training at a higher level the Teaching course remains in operation and the teachers trained by it continue to be hired. This article is a document research, and aims to analyze the policy

Mestre em Educação pela Universidade Regional de Blumenau; Licenciada em Pedagogia pela Universidade Federal de Alfenas; https://orcid.org/0000-0002-4789-916X; http://lattes.cnpq.br/8193559679756169.

2 Doutora em Ciências Sociais pela Pontificia Universidade Católica de São Paulo; Mestre em Educação pela Universidade Regional de Blumenau; https://orcid.org/0000-0003-1667-4643; http://lattes.cnpq.br/3699065025945919. 
of teacher training. Its specific objectives are to contextualize the teachers training at the secondary level in Brazil. And discuss the teacher education policy based on the analysis methodology of the Policy Cycle approach proposed by Ball and his collaborators. The discussion is anchored mainly in Ball, Foucault, Mainardes, Tanuri, Villela and Schaffrath. Although there are laws that point to the higher level as a privileged locus for teacher training, they did not mean the end of middle level training. The same educational system that puts in check the training of teachers in the middle level, offers this training and hires the teachers trained by it. Middle and higher level training cohabit in the context of practice. Keywords: High school. Higher education. Teacher training. Public policy.

Resumen: La formación de profesores para la Educación Infantil y años iniciales de la Enseñanza Primaria tenía como un locus para suceder el nivel secundario. En 1996, con la promulgación de la Ley de Directrices y Bases de la Educación Brasileña (LDB) n. 9.394, esa modalidad de formación docente fue inmersa en un ambiguo contexto. Al mismo tiempo en que la legislación prevé la formación docente a nivel superior el curso del Magisterio permanece en funcionamiento y los profesores formados por él continúan siendo contratados. Este artículo es una investigación documental, y tiene por objetivo analizar la política de formación de los profesores. Siendo sus objetivos específicos contextualizar la formación de profesores a nivel secundario en el Brasil. Y discutir la política de formación de los profesores a partir de la metodología de análisis de abordaje del Ciclo de Políticas propuesto por Ball y sus colaboradores. La discusión se basa principalmente en Ball, Foucault, Mainardes, Tanuri, Villela y Schaffrath. A pesar de haber leyes que apuntan el nivel superior como un locus privilegiado para la formación del profesor, ellas no significan el fin de la formación a nivel secundario. El mismo sistema educacional que coloca en jaque la formación de profesores a nivel secundario, ofrece esa formación y contrata a los docentes formados por ella. La formación a nivel secundario y en nivel superior coexisten en el contexto de la práctica.

Palabras clave: Enseñanza secundaria. Enseñanza superior. Formación de profesores. Política púbica.

Recebido em 28 de janeiro de 2018 Aceito em 06 de novembro de 2018

Publicado em 19 de fevereiro de 2019

\section{INTRODUÇÃO}

A formação de professores para a Educação Infantil e anos iniciais do Ensino Fundamental tinha como lócus para acontecer no nível médio. No entanto, em 1996, com a promulgação da nova Lei de Diretrizes e Bases da Educação Nacional (LDB n. 9.394/96), essa modalidade de formação docente foi imersa em um ambíguo contexto, e sua validade passa a ser questionada. Ao mesmo tempo que a legislação prevê a formação docente em nível 
superior, o curso de Magistério permanece em funcionamento, e, assim, os professores que se formam neste continuam sendo contratados. A LDB n. 9.394 valida o nível médio como formação inicial para a docência em seu artigo 62:

\begin{abstract}
A formação de docentes para atuar na educação básica far-se-á em nivel superior, em curso de licenciatura, de graduação plena, em universidades e institutos superiores de educação, admitida, como formação mínima para o exercício do magistério na educação infantil e nas quatro primeiras séries do ensino fundamental, oferecida em nível médio, na modalidade Normal. (BRASIL, 1996, grifo nosso).
\end{abstract}

0 artigo 87 , inciso $4^{\circ}$, da referida Lei prescrevia que "Até o fim da Década da Educação ${ }^{3}$ somente serão admitidos professores habilitados em nível superior ou formados por treinamento em serviço." (BRASIL, 1996), prescrição esta que não foi efetivada até o ano 2017. Isso pode ser comprovado quando se observa o Edital n. 1.960/2016/SED da Secretaria de Estadual de Educação de Santa Catarina. Aquele que aspira a ser professor na rede estadual nos anos iniciais do Ensino Fundamental precisa comprovar “- Diploma e histórico escolar de conclusão de curso de licenciatura plena em Pedagogia; ou Curso de licenciatura plena em Pedagogia Séries Iniciais; ou diploma/certificado de conclusão de curso Normal Superior; ou diploma/Certificado de Conclusão do Magistério." (ASSOCIAÇÃO CATARINENSE DAS FUNDAÇÕES EDUCACIONAIS, 2016, p. 2, grifo nosso), os chamados habilitados.

Este estudo teve por objetivo analisar a trajetória da política que altera a formação dos professores do nível médio para o nível superior. Como metodologia de análise foi utilizado o policy cycle approach, abordagem do ciclo de políticas, proposta por Stephen Ball e seus colaboradores. Segundo Mainardes (2006), a abordagem do ciclo de políticas é um referencial analítico de grande utilidade para uma análise dos programas e políticas educacionais. 0 autor argumenta que essa abordagem permite uma análise crítica da trajetória desses programas e políticas educacionais a partir da sua formulação inicial até a sua implementação.

0 texto está dividido em quatro partes: a primeira é uma introdução, cujo objetivo é fazer as primeiras apresentações do que é discutido no artigo. A segunda consiste em uma contextualização da formação de professores em nível médio no Brasil, sendo utilizados os seguintes autores: Daros e Daniel (2008), Schaffrath (2008, 2002, 1999), Tanuri (2000), Villela (2008, 2011), entre outros. A terceira parte, partindo da abordagem do ciclo de políticas, traz uma discussão sobre as influências da política que desloca a formação de professores do nível médio para o superior. Como embasamento teórico são utilizados Ball (1994) e Mainardes (2006), Foucault (2002a, 2002b), e, por fim, são tecidas algumas considerações.

3 A Década da Educação refere-se ao período de 1997 a 2007, conforme artigo 87 da LDB (BRASIL, 1996). 


\section{A FORMAÇÃO DE PROFESSORES EM NÍUEL MÉDIO: CONTEXTUALIZANDO UMA POLÍTICA}

A Revolução Francesa foi um dos marcos históricos da transformação de uma sociedade feudal para uma capitalista. Respaldada pelo movimento lluminista da época, cuja principal característica era a defesa das explicações científicas para a sociedade em detrimento de explicações divinas, os ideais da Revolução Francesa postulavam a instituição de uma escola laica, popular, ${ }^{4}$ pública e obrigatória. 0 Estado burguês criou as condições para uma estruturação da rede pública de ensino, bem como foi sua preocupação a capacitação dos profissionais que atuariam nessas escolas (SCHAFFRATH, 2008). A formação de professores é uma necessidade inventada juntamente à criação da escola. Assim como as escolas destinadas à formação de professores, as chamadas Escolas Normais também são uma invenção (TANURI, 2000; SCHAFFRATH, 2008).

No Brasil, a primeira iniciativa de formação docente foi na época Imperial. Sob o governo do Regente Diogo Antônio Feijó, em 1835, é fundada a primeira Escola Normal em Niterói, Província do Rio de Janeiro, sob as normativas do Decreto n. 10, de 1835 (TANURI, 2000). Essa Escola foi idealizada e organizada pelo presidente e vice-presidente da supracitada província, a saber, Joaquim José Rodrigues Torres e Paulino José Soares de Souza (VILLELA, 2008). Eles pertenciam a um grupo que se manteve no poder até 1860 , denominado saquaremas, que para manter sua supremacia política se organizou não somente na esfera da coerção, - que salvaguardava a segurança social, como também conquistou o consenso no âmbito ideológico por meio da fundação de instituições que apoiavam politicamente seus objetivos (VILLELA, 2008).

A Escola Normal de Niterói foi criada com a finalidade de habilitar aqueles que pretendiam ingressar no magistério e os professores atuantes que ainda não tinham formação (TANURI, 2000). No entanto, ela não perdurou por muitos anos, sendo suprimida em 1849 (TANURI, 2000) pelas mãos do Tenente Coronel José da Costa Azevedo, que ocupava o cargo de diretor da instituição, o qual era muito meticuloso com a aprendizagem de seus futuros docentes e somente permitia a formatura após o completo domínio dos conteúdos, o que atrasava o processo (VILLELA, 1990 apud VILLELA, 2008). Essa rigidez de formação esbarrava com os anseios dos governantes. Para eles, a formação de professores deveria ser rápida a fim de suprir a demanda nas escolas primárias, necessidade que se acentuava em razão da baixa procura pela profissão docente. Esse desacordo culminou no fechamento da primeira Escola Normal brasileira (VILLELA, 2008) pelo mesmo grupo que a criou, uma vez que não estava atendendo a seus subjacentes interesses políticos. 
Inventa-se outro procedimento para a formação dos professores das escolas primárias por meio do modelo austríaco-holandês, os chamados professores adjuntos (TANURI, 2000; VILLELA, 2008). Conforme Villela (2008, p. 34), “[...] tratava-se de aproveitar alunos pobres ou filhos de professores como adjuntos de outros mestres até que pudessem reger suas próprias turmas." Tanuri (2000, p. 65) explica que "Tal sistema consistia em empregar aprendizes como auxiliares de professores em exercício, de modo a prepará-los para o desempenho da profissão docente de maneira estritamente prática, sem qualquer base teórica." E, inversamente proporcional ao descuido com a instrução teórica do professor, está a intensa preocupação com o controle desse mesmo professor, "0s professores poderiam até ser mal formados contanto que fossem bem vigiados." (VILLELA, 2008, p. 34 ). 0 interesse era que a escola e os professores propagassem os valores do grupo que estava no poder, uma educação moralizante e não uma educação voltada para a propagação de conhecimentos (VILLELA, 2008).

Juntamente ao novo modelo de formação docente inventa-se uma divisão para as escolas: as escolas de $1^{a}$ classe e de $2^{a}$ classe. Para a $1^{a}$ classe, professores adjuntos; para a $2^{a}$ classe, professores formados. 0 intuito dessa divisão era o aumento do número de escolas, em detrimento à qualidade do ensino que era oferecido (VILLELA, 2008). 0 interesse não era uma instrução intelectual de qualidade, "Desejava-se que os alunos das escolas públicas passassem nas instituições apenas o tempo suficiente para que thes fossem incutidos certos padrões morais e religiosos que os colocassem no patamar da civilização, de acordo com as conveniências do Estado conservador." (VILLELA, 2008, p. 34).

A intenção era formar professores a fim de educar alunos dentro dos padrões considerados verdadeiros para a referida época e satisfazer o grupo senhorial dos saquaremas que estavam no governo. Os professores eram a ponte que levaria esses valores morais e religiosos à população. Quanto à Escola Normal, para Villela (2008, p. 34), "[...] pôde-se concluir que na primeira fase sua existência ligou-se à consolidação do poder de uma facção da classe senhorial 'os saquaremas', e a conseqüente construção de sua hegemonia enquanto dirigentes do Estado imperial brasileiro."

Assim como aconteceu com a Escola Normal de Niterói, as demais iniciativas de Escolas Normais provinciais não foram muito fecundas, uma vez que "[...] em todas as províncias as escolas normais tiveram uma trajetória incerta e atribulada, submetidas a um processo contínuo de criação e extinção." (TANURI, 2000, p. 64).

Até então, não se validava a escola como necessária, o Brasil era um país agrário e alicerçado na mão de obra escrava (TANURI, 2000). Mas, no final do século XIX e começo do século XX, a modernidade chega ao Brasil, "A partir de 1868/70, transformações de ordem ideológica, política e cultural seriam acompanhadas de intensa movimentação de idéias, com profundas repercussões no setor educacional, que passava a assumir uma importância até 
então não vislumbrada." (TANURI, 2000, p. 66). Em meio a um cenário de industrialização do País e à consequente necessidade de trabalhadores especializados, "A educação aliava-se ao desejo de modernização das classes dominantes, pela necessidade que a produção tinha de contar com trabalhadores especializados." (RABELO; MARTINS, 2006, p. 6171).

A educação assumindo essa importância torna a formação de professores importante também. Tanuri (2000, p. 64) afirma que “É no contexto desse ideário de popularização do ensino que as escolas normais passam a ser reclamadas com maior constância e coroadas de algum êxito", havendo um aumento no número de Escolas Normais. Apesar dessa valorização da educação, Daros e Daniel (2008) afirmam que a formação de professores chega à República sem grandes alterações. Somente nos anos 1935 e 1939 novas configurações são propostas para a Escola Normal. 0 projeto urbano e liberal que se instalava no País tinha como base a ciência; houve a inserção e a valorização das ciências tidas como essenciais para a compreensão da nova função da escola, como, por exemplo, a Biologia, a Psicologia e a Sociologia. No currículo das escolas de formação do professorado, essas novas disciplinas colaboraram para a produção de outras concepções sobre o campo educacional (DAROS; DANIEL, 2008).

0 Brasil se modernizava em um intenso processo de industrialização e urbanização. Segundo Nunes (1994), foi justamente nos anos 1920 e 1930 que o paradigma moderno que fora esboçado na sociedade brasileira no final do século XIX e início do século XX se configura com clareza. Nesse cenário, os educadores brasileiros tiveram ampla responsabilidade tanto em discutir o tema da modernidade quanto nos seus projetos políticos, apoiados em certa visão de sociedade e de povo brasileiro (NUNES, 1994). Liderando grandes reformas de instrução pública, ${ }^{5}$ aqueles que trabalhavam nos grandes centros urbanos criaram não apenas a possibilidade de estruturar um campo de identificação, mas também interviram sobremaneira na ordenação simbólica das cidades, construindo novas representações do urbano e do papel do educador dentro dele (NUNES, 1994).

A escola passa a ter outras configurações no espaço urbano. Nunes (2003, p. 374, grifo do autor) acrescenta que:

é no espaço das cidades, com diferentes ritmos e intensidades, que as
escolas deixam de configurar-se como extensão do campo familiar, privado
e religioso e, gradativamente, vão integrando uma rede escolar desenhada
pelos governos municipais. Essa rede substituiu as escolas isoladas e definiu
limites do poder, às vezes abusivo, de diretores e inspetores escolares.
Essa mudança exigiu a intervenção não só nos aspectos materiais da

5 A título de exemplo, a Reforma de Educação do Distrito Federal em meados de 1930, empreendida por Anísio Teixeira (19001971), da qual participaram grandes intelectuais, entre eles Cândido Portinari, Cecilia Meireles, Heitor Villa-Lobos, entre outros (NUNES, 1994). 
escola, o que envolveu a produção de um novo espaço com prédios e material didático pertinente aos novos objetivos educacionais, mas também em seus aspectos simbólicos, pois almejava-se da escola primária mais do que novas carteiras, quadros ou salas. Pretendia-se construir nela um estado de espírito moderno.

A nova configuração escolar objetivava uma transformação profunda do habitus pedagógico, aliando um processo de renovação escolar por meio de uma renovação da formação docente e uma intensa tentativa de reformar os costumes das famílias que mandavam seus filhos para a escola (NUNES, 2003).

Uma nova leitura do urbano era paulatinamente construída pelo esforço ideologizador de toda uma geração de educadores. [...] Havia uma cultura urbana em processo acelerado de transformação a ser decifrada e cabia à escola ensinar hábitos que ajudassem as crianças mais pobres a interpretar a realidade. (NUNES, 1994, p. 197).

Daros e Daniel (2008, p. 253) apontam que "Essas reformas estavam em consonância com o processo de centralização autoritária vivida no país, quando Getúlio Vargas, especialmente durante a Vigência do Estado Novo (1937-1945), manteve sob controle o espaço público com rigorosa vigilância da vida política e social brasileira." Nesse mesmo período, por iniciativa do Ministro de Getúlio Vargas, Gustavo Capanema, é iniciada a reforma de alguns ramos do sistema de ensino. Essas reformas foram nomeadas de Leis Orgânicas do Ensino (ROMANELLI, 2001).

Nos três anos finais do Estado Novo, foram executados os seguintes decretos-lei: Decreto-lei n. 4.073, de 30 de janeiro de 1942, que organizou o ensino industrial; Decretolei n. 4.048, de 22 de janeiro de 1942, responsável pela criação do Serviço Nacional de Aprendizagem Industrial (SENAI); Decreto-lei n. 4.244, de 09 de abril de 1942, pela organização do ensino secundário em dois ciclos: o ginasial, de quatro anos, e o colegial, de três anos; e Decreto-lei n. 6.141, 28 de dezembro de 1943, responsável pela reforma do ensino comercial (ROMANELLI, 2001).

Em 1946, no governo provisório, vindo após a queda de Vargas, sob o Governo de José Linhares, e tendo como Ministro da Educação Raul Leitão da Cunha, foram sancionados mais quatro decretos-lei. São eles: Decreto-lei n. 8.529, de 02 de janeiro de 1946 lorganização do ensino primário nacional); Decreto-lei n. 8.530, de 02 de janeiro de 1946 (organização do ensino normal); Decretos-lei n. 8.621 e 8.622, 10 de janeiro de 1946 (criação do Serviço Nacional de Aprendizagem Comercial (SENAC)); e Decreto-lei n. 9.613, de 20 de agosto de 1946 (organização do ensino agrícola) (ROMANELLI, 2001). 
Quinze anos após o Decreto-lei n. 8.530, em 1961, o curso Normal passa a ser regido pela Lei de Diretrizes e Bases da Educação Nacional, Lei n. 4.024, de 20 de dezembro de 1961, que em seu capítulo IV estabelece:

\begin{abstract}
Art. 52.0 ensino normal tem por fim a formação de professôres, orientadores, supervisores e administradores escolares destinados ao ensino primário, e o desenvolvimento dos conhecimentos técnicos relativos à educação da infância. Art. 53. A formação de docentes para o ensino primário far-se-á: a) em escola normal de grau ginasial no mínimo de quatro séries anuais onde além das disciplinas obrigatórias do curso secundário ginasial será ministrada preparação pedagógica; b) em escola normal de grau colegial, de três séries anuais, no mínimo, em prosseguimento ao vetado grau ginasial. Art. 54. As escolas normais, de grau ginasial expedirão o diploma de regente de ensino primário, e, as de grau colegial, o de professor primário. Art. 55. 0s institutos de educação além dos cursos de grau médio referidos no artigo 53 , ministrarão cursos de especialização, de administradores escolares e de aperfeiçoamento, abertos aos graduados em escolas normais de grau colegial. (BRASIL, 1961).
\end{abstract}

A legislação supracitada regulamentou o curso Normal até 1971. Em meio ao regime militar e sob o governo do então presidente General Médici (1969-1974) a LDB de 1961 foi substituída pela Lei $n$. 5.962, de 1 de agosto de 1971. Esta fixava as novas diretrizes e bases para o ensino de $1^{\circ}$ e $2^{\circ}$ graus e outras providências. Seu capítulo V assevera acerca da formação de professores:

\footnotetext{
Art. 29. A formação de professôres e especialistas para o ensino de $1^{\circ} \mathrm{e}$ $2^{\circ}$ graus será feita em níveis que se elevem progressivamente, ajustandose às diferenças culturais de cada região do País, e com orientação que atenda aos objetivos específicos de cada grau, às características das disciplinas, áreas de estudo ou atividades e às fases de desenvolvimento dos educandos. Art. 30. Exigir-se-á como formação mínima para o exercício do magistério: a) no ensino de $1^{\circ}$ grau, da $1^{a}$ à $4^{a}$ séries, habilitação específica de $2^{\circ}$ grau; b) no ensino de $1^{\circ}$ grau, da $1^{a}$ à $8^{a}$ séries, habilitação específica de grau superior, ao nivel de graduação, representada por licenciatura de $1^{\circ}$ grau obtida em curso de curta duração; c) em todo o ensino de $1^{\circ} \mathrm{e}$ $2^{\circ}$ graus, habilitação específica obtida em curso superior de graduação correspondente a licenciatura plena. $\S 1^{\circ}$ Os professôres a que se refere a letra a poderão lecionar na $5^{a}$ e $6^{a}$ séries do ensino de $1^{\circ}$ grau se a sua habilitação houver sido obtida em quatro séries ou, quando em três mediante estudos adicionais correspondentes a um ano letivo que incluirão, quando fôr o caso, formação pedagógica. $\S 2^{\circ} 0$ s professôres a que se refere a letra $b$ poderão alcançar, no exerćicio do magistério, a $2^{a}$ série do ensino de $2^{\circ}$ grau mediante estudos adicionais correspondentes no mínimo a um ano letivo. $\S 3^{\circ} 0$ s estudos adicionais referidos nos parágrafos anteriores poderão ser objeto de aproveitamento em cursos ulteriores. (BRASLL, 1971).
} 
Por sua vez, a LDB de 1971 foi substituída no final de 1996, após a abertura política e a promulgação da Constituição Federal de 1988, pela Lei n. 9.394, que propõe a formação de professores em nível superior e afirma a legitimidade da formação em nível médio:

\begin{abstract}
Art. 62. A formação de docentes para atuar na educação básica farse-á em nível superior, em curso de licenciatura, de graduação plena, em universidades e institutos superiores de educação, admitida, como formação mínima para o exercício do magistério na educação infantil e nas quatro primeiras séries do ensino fundamental, a oferecida em nível médio na modalidade Normal. (BRASLL, 1996, grifo nosso).
\end{abstract}

No entanto, constata-se uma indecisão no que tange à formação docente em nível médio, pois ora a referida Lei valida essa formação (artigo 62), ora ela aponta que não serão mais aceitos professores sem o nível superior (artigo 87) em um determinado prazo. Retomando o artigo 87, inciso $4^{\circ}$, da LDB n. 9.394, este determina que “até o fim da Década da Educação ${ }^{6}$ somente serão admitidos professores habilitados em nível superior ou formados por treinamento em serviço." (BRASIL, 1996).

Essa dubiedade se mantém com a Lei n. 12.796, de abril de 2013, que altera a LDB n. 9.394/96. Revoga-se o inciso $4^{\circ}$ do artigo 87 cinco anos após o prazo ter terminado e volta-se a legitimar o curso de Magistério como formação inicial para professores (BRASIL, 2013).

Em 2014, é aprovada a Lei n. 13.005, que estabelece o Plano Nacional da Educação, o qual é uma legislação ordinária com vigência de 10 anos a contar a partir de junho de 2014 , que estabelece diretrizes, metas e estratégias para a educação (BRASIL, 2014). Contrariando a Lei n. 12.796 e retomando o artigo 84 da LDB, o PNE (Lei n. 13.005/2014) estabelece como sua meta 15:

\footnotetext{
Garantir, em regime de colaboração entre a União, os Estados, o Distrito Federal e os Municípios, no prazo de 1 (um) ano de vigência deste PNE, politica nacional de formação dos profissionais da educação de que tratam os incisos l, II e III do caput do art. 61 da Lei $n^{\circ}$ 9.394, de 20 de dezembro de 1996, assegurado que todos os professores e as professoras da educação básica possuam formação espećfica de nível superior, obtida em curso de licenciatura na área de conhecimento em que atuam. (BRASIL, 2014, p. 48, grifo nosso).
}

Essa ambiguidade nas legislações colocou o curso de Magistério em um movimento oscilatório entre "será aceito e não será mais" como formação inicial para aqueles

A década da educação refere-se ao período de 1997 a 2007, conforme artigo 87 da LDB (BRASIL, 1996). 
que pretendem lecionar nos primeiros anos do Ensino Fundamental e na Educação Infantil, condição esta que permanece na contemporaneidade.

Essa breve descrição das políticas de formação de professores expõe que até a promulgação da LDB n. 9.394, em 1996, a legitimidade do curso de formação de professores em nível médio não havia sido questionada. É a partir da metodologia de análise Abordagem do Ciclo de Políticas proposto por Ball (1994) que se analisa a política de formação de professores nos contextos de influência e produção de textos.

\section{DO MÉDIO PARA O SUPERIOR: AS POLÍTICAS E SUAS INFLUÊNCIAS}

Até meados dos anos 1990, a formação de professores em nível médio era legitimada pelas políticas educacionais brasileiras. Até então, sua validade não havia sido questionada, era o nível médio o lócus privilegiado para a formação do professor da Educação Infantil e anos iniciais do Ensino Fundamental. A indagação é: em meados dos anos 1990, que influências sofreu a política educacional no que se refere ao lócus de formação docente?

É a partir do policy cycle approach, abordagem do ciclo de políticas, proposta por Stephen Ball e seus colaboradores, que se analisa essa mudança da política de formação de professores. Ball afirma que " 0 principal ponto que gostaria de destacar é o de que o ciclo de políticas é um método. Ele não diz respeito à explicação das políticas. É uma maneira de pesquisar e teorizar as políticas." (MAINARDES; MARCONDES, 2009, p. 305, grifo do autor).

Inicialmente "Os autores propuseram um ciclo contínuo constituído por três contextos principais: o contexto de influência, o contexto da produção de texto e o contexto da prática. Esses contextos estão inter-relacionados, não têm uma dimensão temporal ou sequencial e não são etapas lineares." (MAINARDES, 2006, p. 49). Ball enfatiza que "0 ciclo de políticas não tem a intenção de ser uma descrição das políticas, é uma maneira de pensar as políticas e saber como elas são feitas." (MAINARDES; MARCONDES, 2009, p. 305).

Uma política pode ser compreendida como texto e como discurso (BALL, 1994). Entendendo discurso como "[...] um conjunto de regras anônimas, históricas sempre determinadas no tempo espaço, que definiram em uma dada época, e para uma área social, econômica, geográfica, ou linguística dada, as condições de exercício da função enunciativa." (FOUCAULT, 2002a, p. 136). Enquanto texto, a política terá uma pluralidade de leituras em razão da pluralidade de leitores. Esse texto é produto de diversas influências e agendas, sendo que a sua formulação envolve intenções e negociações no interior do Estado e do processo de 
formulação dessa política. Apenas algumas dessas influências e agendas serão legitimadas, e somente algumas vozes serão ouvidas (MAINARDES, 2006).

A política entendida como texto e a política entendida como discurso são conceituações que se complementam, uma vez que a política como discurso dá ênfase aos limites impostos pelo próprio discurso, em contrapartida, na política como texto, a ênfase está no controle que está nas mãos dos leitores da política (MAINARDES, 2006). Ball (1994, p. 23, tradução nossa) afirma que "A política como discurso pode ter o efeito de redistribuir voz, sendo que às vezes não importa o que alguns dizem, já que somente certas vozes serão ouvidas e consideradas." ${ }^{\prime 7}$ Os dois são processos complexos já que os textos não são apenas o que eles aparentam ser em sua superfície.

Ball (1994), posteriormente, ampliou em dois contextos a Abordagem do Ciclo de Políticas, são eles: o contexto de resultados e efeitos - contexto que envolve questões de justiça, liberdade individual e igualdade; e o contexto de estratégia política - "Esse contexto envolve a identificação de um conjunto de atividades sociais e políticas que seriam necessárias para lidar com as desigualdades criadas ou reproduzidas pela política investigada." (MAINARDES, 2006, p. 55).

0 primeiro contexto é o de influência entendido como precursor das políticas públicas (BALL, 1994).

\footnotetext{
É nesse contexto que grupos de interesse disputam para influenciar a definição das finalidades sociais da educação e do que significa ser educado. Atuam nesse contexto as redes sociais dentro e em torno de partidos políticos, do governo e do processo legislativo. É também nesse contexto que os conceitos adquirem legitimidade e formam um discurso de base para a política. (MAINARDES, 2006, p. 51).
}

0 discurso político que está sendo formado ora pode ser apoiado, ora pode ser desafiado por princípios ou argumentos que estão operando, especialmente por meio da comunicação social, como também essa influência pode ser exercida por comissões e grupos representativos (MAINARDES, 2006).

São apontados por Ball duas formas para o contexto de influências internacionais: a influência por fluxo de ideias, que pode ser por meio de empréstimos de políticas, disseminação internacional de ideias ou venda de soluções no mercado político e acadêmico (MAINARDES, 2006). 0 outro modo de influência relaciona-se ao patrocínio, até mesmo com a imposição de saidas ofertadas por agências multilaterais (MAINARDES, 2006).

\footnotetext{
"L... policy as discourse may have the effect of redistributing voice', so that it does not matter what some people say or think, and only certain voices can be heard as meaningful or authoritative."
} 
A política de formação de professores foi influenciada internacionalmente de ambas as maneiras. Houve a influência pelo fluxo de ideias, ideias essas produzidas e disseminadas por organizações e instituições internacionais. Entre elas estão: a Conferência Mundial de Educação para Todos (1990), que teve como financiadores a Unesco, ${ }^{8}$ a Unicef, ${ }^{9}$ o PNUD ${ }^{10}$ e o Banco Mundial; o documento Transformación Productiva con Equidad, redigido pela Cepal" (COMISSÃO ECONÔMICA PARA A AMÉRICA LATINA E 0 CARIBE, 1990); o relatório da Comissão Internacional sobre Educação para o Século XXI (1998), intitulado Educação: um tesouro a descobrir, redigido a partir de uma convocação da Unesco; as diretrizes do Promedlac V'21 (1993); e o documento Prioridades y Estrategias para la Educación (1996), confeccionado pelo Banco Mundial (SHIROMA; MORAES; EVANGELISTA, 2011). ${ }^{13}$

Na Conferência Mundial de Educação para Todos ocorrida em 1990 na Tailândia, foi produzida a Declaração Mundial sobre Educação para Todos: Satisfação das Necessidades Básicas de Aprendizagem, que estabelecia um acordo entre as nações participantes para assegurar uma educação básica de qualidade (UNESCO, 1990).

0 documento Transformación Productiva con Equidad da Cepal (COMISSÃO ECONÔMICA PARA A AMÉRICA LATINA E 0 CARIBE, 1990,14 p. 10): $:$ "La propuesta gira en torno a la que se considera tarea primordial y común a todos los países: la trasformación de las estructuras productivas de la región en um marco de progresiva equidade social." Um dos elementos propositivos desse documento era a formação de recursos humanos. Uma das estratégias sugeridas era a ampliação da formação em suas distintas fases e âmbitos, ciclos pré-escolares, básico e secundários, universidades, centros de pesquisa, sistemas de capacitação, sistema de educação popular e de adultos e programas de reciclagem ocupacional (COMISSÃO ECONÔMICA PARA A AMÉRICA LATINA E O CARIBE, 1990).

0 relatório da Comissão Internacional sobre Educação para o Século XXI, também chamado de Relatório Delors, aponta a necessidade da formação inicial de professores em nivel superior como uma das medidas para melhorar a qualidade dos professores: 
Estabelecer laços mais estreitos entre as universidades e os institutos de formação de futuros professores do primário e do secundário. A longo prazo, o objetivo deverá ser fazer com que todos os professores, mas em especial os do secundário, tenham freqüentado estudos superiores, sendo a sua formação assegurada em cooperação com as universidades ou mesmo em contexto universitário. (DELORS, $1998,{ }^{16}$ p. 159 , grifo nosso).

0 Promedlac $V$ também enfatiza a necessidade de formação e aperfeiçoamento docente, sugerindo complementações para as práticas que os países executavam até então para formar seu professorado, entre elas a necessidade do fortalecimento de "[...] los centros de formación docente elevando el nivel de sus formadores." (UNESCO, 1993, p. 38). ${ }^{17}$

Lauglo (2013) resume que o documento Prioridades y Estrategias para la Educación confeccionado pelo Banco Mundial tem por base: a priorização da educação básica que deve ser gratuita, ao contrário da educação secundária e superior que devem ser sujeitas ao pagamento de taxas, bem como enfatiza o estabelecimento de padrões de rendimento e a observação dos resultados da educação com mais atenção, focando no gerenciamento de objetivos e performance. Para a educação superior o documento enfatiza o financiamento privado, colocando a privatização como uma solução. Assim como prescreve o financiamento como forma de ampliar o acesso ao nível superior, também há o encorajamento para o financiamento dos outros níveis de educação (BANCO MUNDIAL, 1996).

Por ser o Banco Mundial a maior fonte de financiamento para a educação dos países de média e baixa renda, isso o torna muito influente junto aos governantes e demais financiadores (LAUGL0, 2013, p. १3), “Esta instituição tem a reputação de impor severas condições - que os países receptores dos empréstimos são obrigados a aceitar - e de envolver pesadamente no arcabouço de propostas que os governos submetem para financiamento."

0 Banco Mundial representa tanto um contexto de influência no sentido de fluxo de ideias quanto se apresenta como uma influência no que tange ao patrocínio, "Ao lado do World Bank, a Organização para Cooperação e Desenvolvimento Econômico (OCDE), a Unesco e o Fundo Monetário Internacional (FMI) podem ser considerados agências que exercem influência sobre o processo de criação de políticas nacionais." (MAINARDES, 2006, p. 52). Para Lauglo (2013, p. 14), "Por meio do Fundo Monetário Internacional (FMl) o Banco Mundial exerce grande influência na política macroeconômica, direcionando e conformando a política educacional." Esses documentos podem ser considerados parte do contexto de influência da política educacional que transmuta a formação docente do nível médio para o nível superior.

\footnotetext{
A data refere-se à edição da publicação à qual se teve acesso.

Tradução nossa: fortalecer os centros de formação docente elevando o nível de seus formadores.
} 
Segundo o contexto da produção de texto, os textos políticos são, em suas diferentes apresentações, textos legais oficiais e textos políticos como também comentários, tanto formais quanto informais, sobre os tais textos oficiais, pronunciamentos, entre outros (MAINARDES, 2006). É importante ressaltar que:

[...] o contexto de influência tem uma relação simbiótica, porém não evidente ou simples, com o segundo contexto, o contexto da produção de texto. Ao passo que o contexto de influência está freqüentemente relacionado com interesses mais estreitos e ideologias dogmáticas, os textos políticos normalmente estão articulados com a linguagem do interesse público mais geral. (MAINARDES, 2006, p. 52).

No que tange tanto às políticas de educação quanto à política de formação de professores, o texto político produzido de maior importância foi a Lei de Diretrizes e Bases da Educação Nacional (9.394/96), criada em 20 de dezembro de 1996, já citada neste trabalho e que em seu artigo 62 estabelece:

\footnotetext{
[...] a formação de docentes para atuar na educação básica far-se-á em nivel superior, em curso de licenciatura, de graduação plena, em universidades e institutos superiores de educação, admitida, como formação mínima para o exercício do magistério na educação infantil e nos 5 (cinco) primeiros anos do ensino fundamental, a oferecida em nível médio na modalidade normal. (BRASIL, 1996).
}

Em seguida, no Título IX Das Disposições Transitórias, em seu artigo 87, inciso $4^{\circ}$, prescreve que, "Até o fim da Década da Educação, ${ }^{18}$ somente serão admitidos professores habilitados em nível superior ou formados por treinamento em serviço." (BRASIL, 1996). Essa ambiguidade da legislação é explicada por Mainardes (2006, p. 52): "Tais textos não são, necessariamente, internamente coerentes e claros, e podem também ser contraditórios. Eles podem usar os termos-chave de modo diverso."

0 terceiro contexto apontado por Ball é o contexto da prática, contexto no qual há a resposta aos textos produzidos e apresenta consequências reais. As políticas não são simplesmente implementadas; é no contexto da prática que as políticas podem ser reinterpretadas e recriadas (MAINARDES, 2006).

Por mais que no contexto de influência a formação de professores deva acontecer em nível superior, e há textos políticos que ratificam isto, como, por exemplo, LDB (1996), PNE (2014), a realidade que se apresenta é outra. No contexto da prática, o curso de Magistério

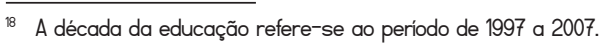


continua formando professores. Em 2014, estavam matriculados no curso de Magistério, oferecido pela rede estadual de Santa Catarina, 4.712 estudantes, distribuídos em 58 escolas. Em 2015, foram abertas novas turmas nas cidades catarinenses de llhota e Gaspar. ${ }^{19}$ Em Blumenau, há uma instituição ligada à rede estadual de ensino que oferece essa formação há mais de 70 anos (1946-2017) ininterruptamente.

0 curso oferecido por essa instituição pode ser ou não cursado concomitantemente com o Ensino Médio. Aceita-se as seguintes configurações: no Ensino Médio $\left(1^{\circ}\right.$ e $2^{\circ}$ anos concluídos) ingressa-se no curso de Magistério, cursam-se mais dois anos e conclui-se o Ensino Médio junto com o Magistério. Para aqueles que já concluíram o Ensino Médio, o curso de Magistério tem duração de dois anos.

No que tange ao ingresso dos estudantes no terceiro ano do curso de Magistério, ou primeiro ano para aqueles que já terminaram o Ensino Médio, os dados cedidos pela secretaria da instituição mostram que, em 2014, foram matriculados 62 estudantes. No ano seguinte, 2015, 39 e em 201660 estudantes. Como demonstra o gráfico a seguir:

Gráfico 1 - Matrículas dos estudantes do $3^{\circ}$ ano nos anos 2014, 2015 e 2016

\section{3ㅇ ANO}

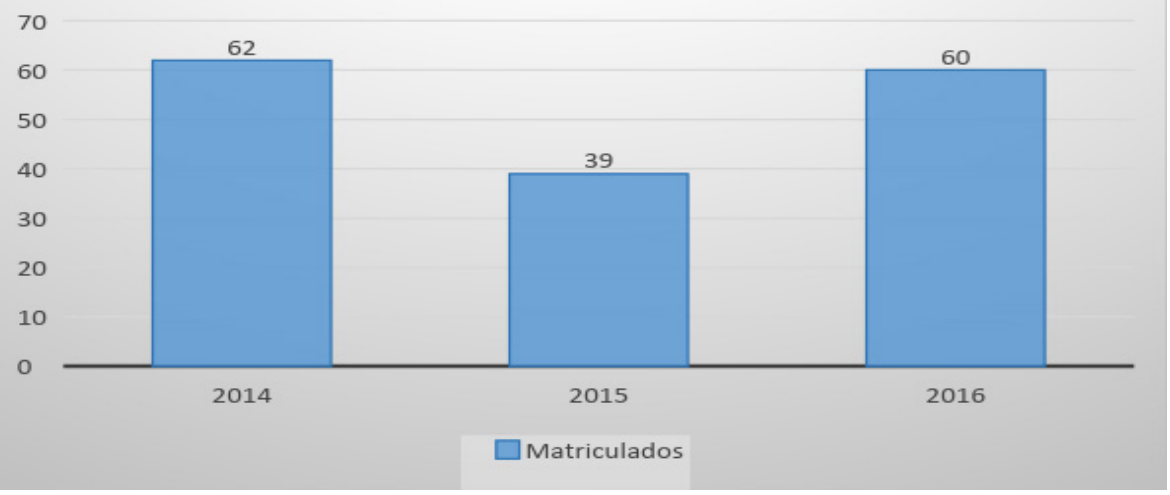

Fonte: os autores.

Quanto ao número de estudantes que concluem o curso, os dados disponibilizados por essa instituição apontam que em 2014 se formaram 19 professores por meio do curso de Magistério oferecido por ela. Em 2015 houve uma redução desse número para 11 docentes formados. Em 2016, os dados apontam que nove professores foram formados, conforme mostra o Gráfico 2:

19 Dados disponibilizados pela Diretoria de Ensino Básico - Gerência de Ensino Médio por e-mail. 
Gráfico 2 - Estudantes formados pelo curso de Magistério oferecido pela instituição pesquisada nos anos 2014 , 2015 e 2016

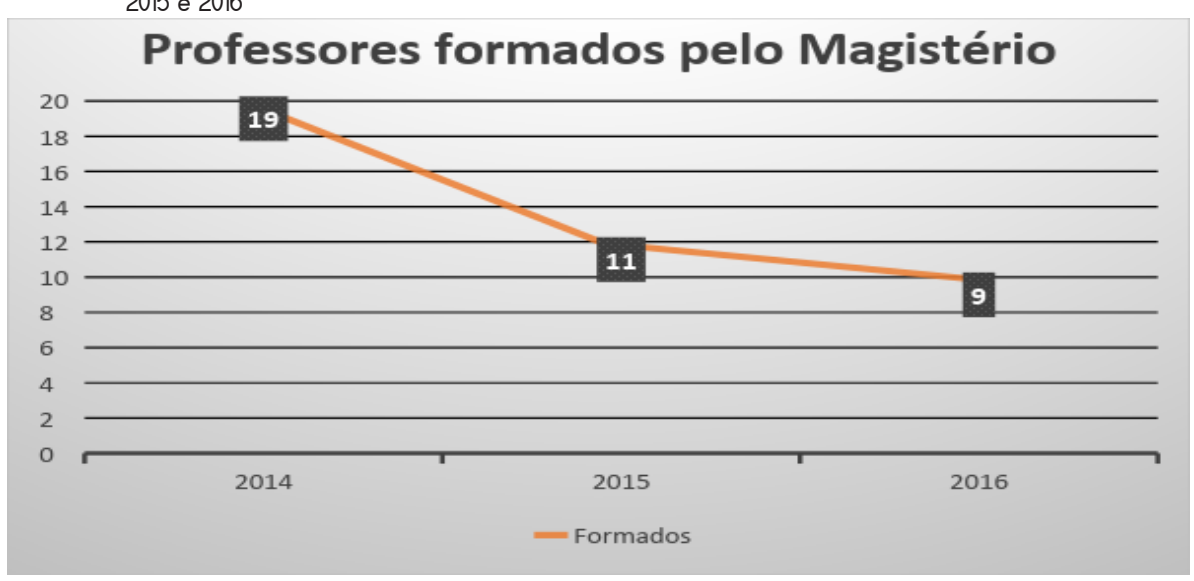

Fonte: os autores.

Os dados inferem que há uma expressiva diferença entre o número de estudantes que ingressam nessa formação e o número de professores formados por ela. A maioria dos matriculados não findam o curso. Mesmo assim, os dados permitem afirmar que, no contexto da prática, ele continua ativo. Não com a expressividade de outrora, mas em atividade.

A mudança na legislação não significou o fim do curso de Magistério. A formação em nível médio e em nível superior coabitam no contexto da prática. Embora haja as legislações que prescrevam a não contratação de professores apenas com a formação em nível médio, estes são bem quistos nas escolas.

Isso pode ser comprovado com os dados do processo seletivo realizado pela prefeitura Municipal de Blumenau. Segundo o Edital n. 004/2015 (BLUMENAU, 2015), válido para os anos 2016 e 2017, para o cargo de professor da Educação Infantil, até junho de 2017, haviam sido convocados 183 professores com habilitação mínima ${ }^{20}$ (formação em nível médio). Para atuar nos anos iniciais do Ensino Fundamental foram convocados 42 professores com essa mesma formação, o que demonstra a oferta de empregos para os professores formados pelo curso de Magistério. Sem essa oferta de trabalho, a formação de professores em nível médio teria um fim em si mesma. Na lógica da lei da oferta e procura, permanece a formação de professores nesse nível uma vez que eles são absorvidos pela escola.

Esses dados ratificam que, mesmo com um contexto de produção de texto que prescreve a formação de professores no nível superior e tendo em vista que a década da

20 0s professores formados em nível médio são convocados quando se esgota a lista dos professores licenciados. 
educação estipulada pela LDB n. 9.394/96 já se findou há 10 anos, a formação em nível médio permanece uma constante no contexto da prática.

Acredita-se que a formação de professores no Magistério ganhará um novo fôlego com a reestruturação do Ensino Médio pela Lei n. 13.415/2017, que estabelece uma parte composta pela Base Nacional Comum Curricular e itinerários formativos no currículo do Ensino Médio, entre elas a formação técnica e profissional, a qual será organizada de acordo com a possibilidade dos sistemas de ensino, necessidade e relevância para o contexto local (BRASIL, 2017).

Diante dessa nova legislação, é mais provável a mudança da lei, legitimando a formação docente em nível médio, do que a efetivação da Meta 15 do Plano Nacional da Educação (Lei n. 13.005/2014), a qual estabelece, mais uma vez (visto que a LDB n. 9.394/96 já havia determinado), a não contratação de professores formados em nível médio.

\section{4 ÚLTIMAS CONSIDERAÇÕES}

A política que transmuta a formação do professor do nível médio para o superior também não é neutra. Ela é o resultado de jogos de interesses, ela foi constituída sobre influências de ideias de organismos internacionais.

Países em desenvolvimento, como é o caso do Brasil, curvam-se diante de exigências de organizações internacionais, visto que financiamentos só são concedidos para aqueles que aceitam tais exigências.

Mesmo produzindo textos em consonância com as exigências internacionais o Brasil, e apontando o nível superior como lócus privilegiado para a formação do professor, essa é uma política que não se efetivou no contexto da prática, pois o nível médio continua formando professores, e esses professores são absorvidos pelo sistema educacional brasileiro. Os editais tanto do Estado de Santa Catarina quanto da Prefeitura de Blumenau são claros quanto ao aceite dos professores formados pelo curso de Magistério em nível médio. 0 mesmo sistema educacional que coloca em xeque a formação de professores em nível médio oferece essa formação e contrata os docentes formados por elas. A legislação aponta para um deslocamento do nível da formação do docente do médio para o superior, no entanto, o curso de Magistério continua sendo uma possibilidade para a inserção na profissão professor.

A intenção não é afirmar que a formação em nível superior é melhor que a formação docente em nível médio. Trata-se de defender a necessidade de uma formação 
docente com qualidade, que articule teoria e prática na e com a escola. Essa indecisão entre pode, não pode mais e agora pode de novo faz com que o curso de Magistério não seja visto. 0 que não se vê, não se discute. Há a urgente necessidade de uma política clara e definida no que se refere à formação de professores.

\section{REFERÊNCIAS}

ASSOCIAÇÃO CATARINENSE DAS FUNDAÇÕES EDUCACIONAIS. Edital Processo Seletivo ACT Educação Básica. 2016. Disponivel em: http://www.acafe.org.br. Acesso em: 13 maio 2016.

BALL, S. J. Educational reform: a critical and post-structural approach. Buckingham: Open University Press, 1994.

BANCO MUNDIAL. Prioridades y estrategias para la educación: examen del Banco Mundial. Washington: Banco Mundial, 1996.

BLUMENAU. Edital n. 004, de 27 de jutho de 2015. A secretária de educação, no uso de suas atribuições legais e regulamentares, torna público o Edital de abertura para realização do Processo Seletivo Público Simplificado $n^{\circ}$ 004/2015, destinado ao preenchimento de vagas temporárias para o quadro de pessoal da Secretaria Municipal de Educação para os anos letivos de 2016 e 2017 [...] Processo Seletivo Público Simplificado n 004/2015 será de responsabilidade da FURB - Universidade Regional de Blumenau. Blumenau: Secretaria Municipal de Educação, 2015. Disponível em: http://www.blumenau. sc.gov.br/atas/viewpublicconcurso.aspx?52. Acesso em: 03 jun. 2017.

BRASIL. Lei n. 4.024, de 20 de dezembro de 1961. Fixa as Diretrizes e Bases da Educação Nacional. Diário Oficial da União, Brasília, DF, 20 dez. 1961.

BRASIL. Lei n. 5.962, de 11 de agosto de 1971. Fixa as Diretrizes e Bases para o ensino de $1^{\circ}$ e $2^{\circ}$ graus, e dá outras providências. Diário Oficial da União, Brasília, DF, 11 ago. 1971.

BRASIL. Lei n. 9.394, 20 de dezembro de 1996. Estabelece as diretrizes e bases da educação nacional. Diário Oficial da União, Brasília, DF, 20 dez. 1996.

BRASIL. Lei n. 12.796, de 04 de abril de 2013. Altera a Lei no 9.394, de 20 de dezembro de 1996, que estabelece as diretrizes e bases da educação nacional, para dispor sobre a formação dos profissionais da educação e dar outras providências. Diário Oficial da União, Brasília, DF, 04 abr. 2013.

BRASIL. Lei n. 13.005, de 25 de junho de 2014. Aprova o Plano Nacional de Educação - PNE e dá outras providências. Diário Oficial da União, Brasília, DF, 25 jun. 2014.

BRASIL. Lei n. 13.415, de 16 de fevereiro de 2017. Altera as Leis ns 9.394, de 20 de dezembro de 1996, que estabelece as diretrizes e bases da educação nacional, e 11.494, [...] e institui a Política de Fomento à Implementação de Escolas de Ensino Médio em Tempo Integral. Diário Oficial da União, Brasília, DF, 16 fev. 2017. 
COMISSÃO ECONÔMICA PARA A AMÉRICA LATINA E O CARIBE. Transformación Productiva com Equidad: la tarea prioritária del desarrollo de América Latina y el Caribe em el los años noventa. Santiago do Chile: Naciones Unidas Comision Economica para América Latina y Caribe, 1990.

DAROS, M. D.; DANIEL, L. S. 0 curso Normal em Santa Catarina: o processo de construção de um projeto de formação de professores coadunado com ideais de nacionalização e "cientifização" do ensino. In: ARAUJO, J. C.; FREITAS, A. M. B.; LOPES, A. de P. C. (org.). As escolas normais no Brasil: do Império à República. Campinas: Alínea, 2008. p. 29-45.

DELORS, J. Educação: um tesouro a descobrir. Brasília, DF: Cortez: MEC: UNESCO, 1998.

FOUCAULT, M. A arqueologia do saber. 6. ed. Rio de Janeiro: Forense Universitária, 2002a.

FOUCAULT, M. Em defesa da sociedade. São Paulo: Martins Fontes, 2002b.

LAUGLO, J. Crítica às prioridades e estratégias do Banco Mundial para a educação. Cadernos de Pesquisa, n. 100, p. 11-36, 2013.

MAINARDES, J. Abordagem do ciclo de políticas: uma contribuição para a análise de políticas educacionais. Educação e Sociedade, v. 27, n. 94, p. 47-69, 2006.

MAINARDES, J.; MARCONDES, M. I. Entrevista com Stephen J. Ball: um diálogo sobre justiça social, pesquisa e política educacional. Educação e Sociedade, Campinas, v. 30, n. 106, p. 303-318, jan./abr. 2009.

NUNES, C. A escola reinventa a cidade. In: HERSCHMANN, M. M.; PEREIRA, C. A. M. (org.). A invenção do Brasil Moderno: medicina, educação e engenharia nos anos 20-30. Rio de Janeiro: Rocco, 1994.

NUNES, C. (Des)Encantos da Modernidade Pedagógica. In: FLLHO, L. M. F.; LOPES, E. M. T.; VEIGA, C. G. (org.). 500 Anos de Educação no Brasil. 3. ed. Belo Horizonte: Autêntica, 2003. p. 371-398.

RABELO, A. 0.; MARTINS, A. M. A mulher no magistério brasileiro: um histórico sobre a feminização do magistério. In: CONGRESSO LUSO BRASILEIRO DE HISTÓRIA DA EDUCAÇÃO, 6., 2006, Uberlândia. Anais... Uberlândia, 2006. p. 6167-6176.

ROMANELLI, 0. 0. História da Educação no Brasil (1930/1973). 26. ed. Petrópolis: Vozes, 2001.

SCHAFFRATH, M. A. S. A Escola Normal Catarinense de 1882: profissão e ornamento. 1999. 146 f. Dissertação (Mestrado em Educação) - Programa de Pós-Graduação em Educação do Centro de Ciências da Educação, Universidade Federal de Santa Catarina, Florianópolis, 1999.

SCHAFFRATH, M. A. S. A proposta curricular da Escola Normal Catarinense de 1892. In: DAROS, M. D.; SCHEIBE, L. (org.) Formação de Professores em Santa Catarina. 1. ed. Florianópolis: NUP/CED, 2002. p. 93-112. 
SCHAFFRATH, M. A. S. Escola normal: o projeto das elites brasileiras para a formação de professores. In: ENCONTRO INTERDISCIPLINAR DE PESQUISA EM ARTES-FACULDADE DE ARTES DO PARANÁ-FAP, 1., 2008, Curitiba. Anais... Curitiba, 2008.

SHIROMA, 0. E.; MORAES, M. C. M.; EVANGELISTA, 0. Política Educacional. 4. ed. Rio de Janeiro: Lamparina, 2011.

TANURI, L. M. História da formação de professores. Revista Brasileira de Educação, n. 14, p. 61-88, 2000.

UNESCO. Boletim $n^{\circ} 31$ do Proyecto Principal de Educación en América Latina y el Caribe. Santiago: Orealc, 1993.

UNESCO. Declaração Mundial sobre Educação para Todos (Conferência de Jomtien). Tailândia: 1990.

VARELA, J.; ALVAREZ-URIA, F. Arqueologia de la Escuela. Madrid: La Piqueta, 1991.

VILLELA H. O. S. 0 mestre-escola e a professora. In: LOPES, E. M. T.; FARIA FLLHO, L. M.; VEIGA, C. G. (org.). 500 anos de educação no Brasil. 3. ed. Belo Horizonte: Autêntica, 2011. p. 95-134.

VILLELA, H. O. S. A primeira escola normal do Brasil: concepções sobre a institucionalização da formação docente no século XIX. In: ARAUJO, J. C.; FREITAS, A. M. B.; LOPES, A. de P. C. (org.). As escolas normais no Brasil: do Império à República. Campinas: Alínea, 2008. p. 29-45.

Endereços para correspondência: Rua Gottlieb Reif, 50, 89031-270, Escola Agrícola, Blumenau, Santa Catarina, Brasil; lilian.alvespereira@yahoo.com.br 